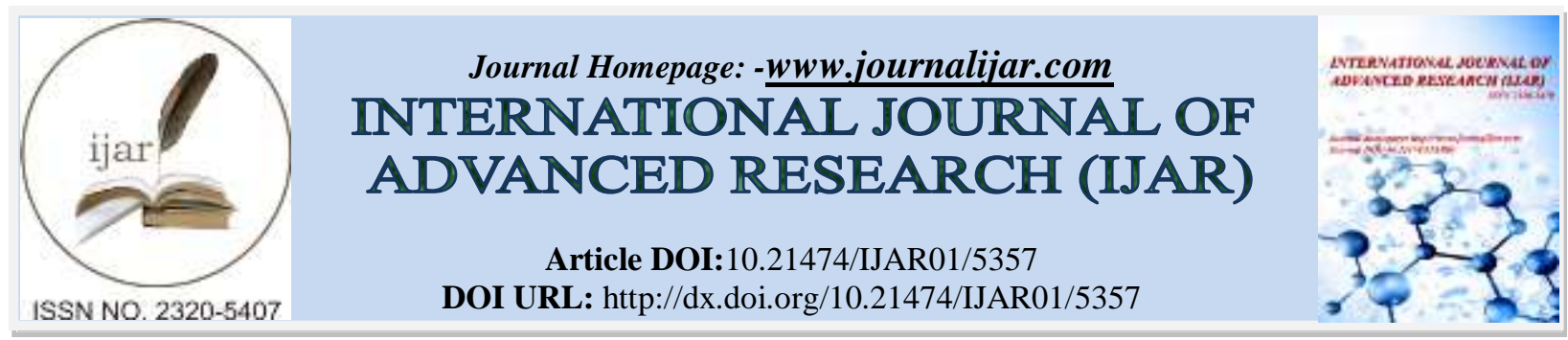

RESEARCH ARTICLE

\title{
EFFECTIVENESS OF HEAL NURSING STRATEGY ON PAIN AND FUNCTIONAL ABILITY AMONG ADULTS WITH KNEE OSTEOARTHRITIS: A PILOT REPORT.
}

1. Ph.D(Scholar), MAHER Chennai.

\author{
Rajeswari. $\mathbf{R}^{1}$ and Dr. Prema $K^{2}$.
}

2. Guide-MAHER Chennai.

\section{Manuscript Info}

Manuscript History

Received: 07 July 2017

Final Accepted: 09 August 2017

Published: September 2017

Key words:-

Knee osteoarthritis, Numerical Pain intensity scale, WOMAC scale, HEAL nursing strategy.

\begin{abstract}
Knee osteoarthritis is a form of degenerative disease affecting the elderly population worldwide. A quantitative quasi experimental study was conducted to find the reliability and feasibility of tool and intervention with 44 samples selected through convenience sampling technique for experimental and control group in orthopedic wards of SVMCHRC, Puducherry. The patients aged between 55-65 years, both gender with clinical symptoms of mild and moderate knee osteoarthritis were included as samples. Demographic and clinical data were collected by structured questionnaires. The Pain and Functional ability were assessed by using Numerical pain intensity scale and modified WOMAC osteoarthritis Index. The HEAL (Hot application, exercise, and education on activity and limitation) nursing strategy was implemented to experimental group (22 patients). The patients were followed for one week. After a week, post test conducted with same questionnaires. The results revealed that the tools used, set criteria for sample selection, the implementation of interventions were highly reliable and feasible for implementation.
\end{abstract}

Copy Right, IJAR, 2017,. All rights reserved.

\section{Introduction:-}

Knee osteoarthritis is a form of degenerative disease of the knee affecting the elderly population worldwide. Studies have shown the prevalence of knee osteoarthritis (KOA) to be $7.50 \%, 10.9 \%$ and $13.6 \%$ in China, India and Bangladesh. A study in Pakistan has shown that $28 \%$ of the urban and $25 \%$ of the rural population have knee osteoarthritis (Iqbal MN,2011).

Osteoarthritis has multifactorial etiologies, which occurs due to interplay between systemic and local factors. Osteoarthritis affects all ages. Injury to the joint, obesity, and genetic susceptibility predispose adolescent athletes to the development of premature osteoarthritis. Previous knee trauma increases the risk of knee OA 3.86 times. Old age, female gender, repetitive use of joint, occupation with knee strain, use of Indian toilets and sedentary lifestyle bone density, muscle weakness, and joint laxity all play roles in the development of joint OA. Determination of risk factors particularly in the weight-bearing joints and their modification may reduce the risk of OA and prevent subsequent pain and disability. Mechanical forces exerted on the joints are a significant cause of OA and one of the most modifiable risk factors as determined by body BMI. 
The consequences are activity avoidance, muscle atrophy, difficulty in performing functional tasks involving ambulation and transfer, and reduced quality of life. Therefore, conservative non-pharmacologic strategies are recommended by all clinical guidelines for the management of OA and meta-analyses supports that the exercises with hot application can be beneficial to reduce the pain and improves the functional limitations. An individualized approach to exercise prescription is required based on an assessment of impairments, patient preference, comorbidities. Maximizing adherence is a key element dictating success of exercise therapy. This can be enhanced by the teaching the clients about the activities and limitations to be carried out during the daily activities.

\section{Objectves:-}

To test the reliability - feasibility of the tool and HEAL nursing strategy on pain and functional ability of adults with knee osteoarthritis.

\section{Methodology:-}

Research Approach:-

Quantitativeapproach was used to evaluate the effectiveness of HEAL nursing strategy.

\section{Research Design:-}

Quasi Experimental Pretest -post test design was used for this research .One experimental group manipulated with HEAL nursing strategies and One control group.

\section{Research Setting:-}

The study was conducted in the orthopedic wards of Sri Venkateshwaraa Medical College Hospital and Research Centre which is 850 beded multi speciality hospital. It has various specialty OPDs and Wards like orthopedic wards, general medical and surgical wards, ENT and opthal wards, obstetric and gyneacology wards for both gender separately. On average getting $45 \%$ of patients aged between 40-65 years. In orthopedic department, getting 40\% of geriatric patients admitted for orthopedic related complaints and $25 \%$ have knee osteoarthritis. On average daily 2-3 patients admitted with knee osteoarthritis, monthly 60-85 patients admitted with knee osteoarthritis.

\section{Research Population:-}

Patients with knee osteoarthritis at Puducherry.

\section{Sample:-}

Patient who have attended SVMCH \&RC with clinical symptoms of knee osteoarthritis

\section{Sample size:-}

The sample size is 440 as determined by power analysis. In that total samples, 220 samples selected for experimental group and 220 samples for control group.

\section{Sampling techniques:-}

Samples were selected using non probability convenience sampling technique

\section{Sampling criteria:-}

Inclusion Criteria:-

1. Patients with clinical symptoms of knee osteoarthritis

2. Patients with Mild and Moderate Knee osteoarthritis

3. Both male and female with clinical symptoms of knee osteoarthritis

4. Patients who were willing to participate in this study

\section{Exclusion Criteria:-}

1. Critically ill patients

2. Patients admitted in ICU

3. Patients with Septic Knee Osteoarthritis

4. Patients with Acute Knee Injury

5. Patients with Severe Osteoarthritis

6. Patients posted for osteoarthritis corrective surgeries 
Tools And Description:-

Part I :-Structured questionnaire for demographic and clinical variables.

Part II:-Numerical pain scale for Pain assessment.

Part III:-Modified WOMAC scale for Functional ability assessment.

\section{Results And Discussion:-}

The reliability of the data collection tools were assessed using inter rater and parallel form reliability respectively and the correlation coefficient $r$-value obtained was 0.81 for the numerical pain intensity scale and 0.9 for the modified Womac scale. These correlation coefficient values are very high and hence, these tools are reliable enough for assessing the effectiveness of HEAL nursing strategy on pain and functional ability among the adults with knee osteoarthritis.

Data were analyzed using descriptive statistics mean and standard deviation, inferential statistics unpaired test to test the effectiveness of HEAL nursing strategy.

Table 1:- showed that the distribution of samples in experimental and control group based on demographic variables. Homogeneity was maintained between the experimental and control group.

Table 2:- showed that the distribution of samples in experimental and control group based on clinical variables. . Homogeneity was maintained between the experimental and control group.

Table 3:- showed that the there is a significant decrease in the pain level between the pretest and post test indicates that the HEAL nursing strategy was effective in reducing the pain.

Table 4:-showed that the there is no significant decrease in the pain level between the pretest and post test among the control group

Table 5:- showed that the Comparison of post-test level of pain intensity scores between the experimental and control group proved that there is a significant reduction in the pain level with HEAL nursing interventions.

Table 6:- showed that the Comparison of post-test level of functional ability scores between the experimental and control group indicated that there is a significant improvement in the level of functional ability among the experimental group.

Table No.1:- Frequency distribution based on Demographic Variables

\begin{tabular}{|c|c|c|c|c|c|}
\hline \multirow[t]{2}{*}{ S.No } & \multirow[t]{2}{*}{ Demographic Variables } & \multicolumn{2}{|c|}{ Experimental Group } & \multicolumn{2}{|c|}{ Control Group } \\
\hline & & $\mathrm{N}$ & $\%$ & $\mathrm{~N}$ & $\%$ \\
\hline \multirow[t]{4}{*}{1.} & \multicolumn{5}{|l|}{ Age in years } \\
\hline & a. $55-60$ & 12 & 54.5 & 11 & 50 \\
\hline & b. $\quad 61 \quad-65$ & 10 & 45.5 & 11 & 50 \\
\hline & c. Above 65 & 0 & 0 & 0 & 0 \\
\hline \multirow[t]{3}{*}{2.} & \multicolumn{5}{|l|}{ Sex } \\
\hline & a. Male & 12 & 54.5 & 10 & 45.5 \\
\hline & b. Female & 10 & 45.5 & 12 & 54.5 \\
\hline \multirow[t]{6}{*}{3} & \multicolumn{5}{|l|}{ Education } \\
\hline & a. illiterate & 8 & 36.4 & 9 & 40.9 \\
\hline & b. $\quad$ Secondary & 7 & 31.8 & 6 & 27.3 \\
\hline & c. Higher secondary & 6 & 27.3 & 5 & 22.7 \\
\hline & d. Graduate & 1 & 4.5 & 2 & 9.1 \\
\hline & e. Postgraduate & 0 & 0 & 0 & 0 \\
\hline \multirow[t]{3}{*}{4} & \multicolumn{5}{|l|}{ Occupation } \\
\hline & a. $\begin{array}{l}\text { Occupation with knee } \\
\text { strain }\end{array}$ & 18 & 81.8 & 16 & 72.7 \\
\hline & b. $\begin{array}{l}\text { Occupation without knee } \\
\text { strain }\end{array}$ & 4 & 18.2 & 6 & 27.3 \\
\hline \multirow[t]{4}{*}{5.} & \multicolumn{5}{|l|}{ Socio Economic status } \\
\hline & a. upper & 2 & 9.1 & 3 & 13.6 \\
\hline & b. middle & 10 & 45.45 & 8 & 36.4 \\
\hline & c. lower & 10 & 45.45 & 11 & 50 \\
\hline
\end{tabular}




\begin{tabular}{|l|l|l|l|l|l|}
\hline \multirow{4}{*}{} & a. Urban & 6 & 27.3 & 7 & 31.8 \\
\cline { 2 - 6 } & b. Rural & 16 & 72.7 & 15 & 68.2 \\
\hline \multirow{3}{*}{7.} & Family history of osteoarthritis & 2 & 9.1 & 2 & 9.1 \\
\cline { 2 - 6 } & a. Yes & 20 & 90.9 & 20 & 90.9 \\
\cline { 2 - 6 } & b. No &
\end{tabular}

Table No.2:- Frequency distribution based on clinical variables.

\begin{tabular}{|c|c|c|c|c|c|}
\hline \multirow[t]{2}{*}{ S.No } & \multirow[t]{2}{*}{ Demographic Variables } & \multicolumn{2}{|c|}{ Experimental Group } & \multicolumn{2}{|c|}{ Control Group } \\
\hline & & $\mathrm{N}$ & $\%$ & $\mathrm{~N}$ & $\%$ \\
\hline \multirow[t]{3}{*}{1.} & \multicolumn{5}{|l|}{ Type of Knee osteoarthritis } \\
\hline & a. Mild & 14 & 63.6 & 12 & 54.5 \\
\hline & b. Moderate & 8 & 36.4 & 10 & 45.5 \\
\hline \multirow[t]{3}{*}{2.} & \multicolumn{5}{|l|}{ Knee affected } \\
\hline & a.Right & 14 & 63.6 & 16 & 72.7 \\
\hline & b.Left & 8 & 36.4 & 6 & 27.3 \\
\hline \multirow[t]{3}{*}{3.} & \multicolumn{5}{|l|}{ Pain in knee joint } \\
\hline & a. Yes & 22 & 100 & 22 & 100 \\
\hline & b.No & 0 & 0 & 0 & 0 \\
\hline \multirow[t]{3}{*}{4.} & \multicolumn{5}{|l|}{ Swelling over joints } \\
\hline & a. Yes & 18 & 81.8 & 15 & 68.2 \\
\hline & b.No & 4 & 18.2 & 7 & 31.8 \\
\hline \multirow[t]{3}{*}{5.} & \multicolumn{5}{|l|}{ Stiffness in joints } \\
\hline & a. Yes & 20 & 90.9 & 18 & 81.8 \\
\hline & b.No & 2 & 9.1 & 4 & 18.2 \\
\hline \multirow[t]{5}{*}{6.} & \multicolumn{5}{|l|}{ Body Mass Index } \\
\hline & a. Under weight $(<18)$ & 1 & 4.5 & 0 & 0 \\
\hline & b. $\quad \operatorname{Normal}(18-24.9)$ & 6 & 27.3 & 8 & 36.4 \\
\hline & c. Over weight(25-29.9) & 10 & 45.5 & 11 & 50 \\
\hline & d. Obese (>30) & 5 & 22.7 & 3 & 13.6 \\
\hline \multirow[t]{3}{*}{7.} & \multicolumn{5}{|l|}{ History of Knee Injury } \\
\hline & a. Yes & 3 & 13.6 & 2 & 9.1 \\
\hline & b. $\quad N o$ & 19 & 86.4 & 20 & 90.9 \\
\hline \multirow[t]{5}{*}{8.} & \multicolumn{5}{|l|}{ Duration of illness } \\
\hline & a. $<1$ year & 0 & 0 & 1 & 4.5 \\
\hline & b. $1-2$ years & 18 & 81.8 & 16 & 72.7 \\
\hline & c. 2-3 years & 2 & 9.1 & 2 & 9.1 \\
\hline & d. $>3$ years & 2 & 9.1 & 3 & 13.6 \\
\hline \multirow[t]{3}{*}{9.} & \multicolumn{5}{|l|}{ Attained Menopause } \\
\hline & a)Yes & 10 & 45.5 & 12 & 54.5 \\
\hline & b)No & 12 & 54.5 & 10 & 45.5 \\
\hline
\end{tabular}


Table No 3:-Frequency and Percentage distribution of pre test and post test level of pain in the Experimental group:

\begin{tabular}{|l|c|c|c|c|}
\hline \multirow{2}{*}{ Level of pain } & \multicolumn{2}{c|}{ Pre test } & \multicolumn{2}{c|}{ Post test } \\
\cline { 2 - 5 } & n & \% & n & 4.5 \\
\hline No pain (0) & 0 & 0.0 & 1 & 63.6 \\
\hline Mild pain (1-3) & 1 & 4.5 & 14 & 22.7 \\
\hline Moderate pain (4-6) & 3 & 13.6 & 5 & 9.2 \\
\hline Severe pain (7 - 9) & 16 & 72.7 & 2 & 0.0 \\
\hline Worst possible pain (10) & 2 & 9.2 & 0 & \\
\hline
\end{tabular}

Table No: 4: Frequency and Percentage distribution of pre test and post test level of pain in the control group. $(\mathrm{N}=22)$

\begin{tabular}{|l|c|c|c|c|}
\hline \multirow{2}{*}{ Level of pain } & Pre test & \multicolumn{2}{c|}{ Post test } \\
\cline { 2 - 5 } & n & \% & 0 & n \\
\hline No pain (0) & 0 & 0 & 1 & 0 \\
\hline Mild pain (1-3) & 1 & 4.5 & 9 & 4.5 \\
\hline Moderate pain (4-6) & 1 & 4.5 & 9 & 40.9 \\
\hline Severe pain (7 -9) & 14 & 63.6 & 3 & \\
\hline Worst possible pain (10) & 6 & 27.4 & 3.9 \\
\hline
\end{tabular}

Table No 5:- Comparison of post-test level of pain intensity scores between the experimental and control group.

\begin{tabular}{|l|c|c|c|}
\hline Post test & Mean & SD & Unpaired t test \\
\hline Experimental Group & 3.1 & 0.085 & 12.497 \\
\hline Control Group & 6.8 & 0.31 & $\mathrm{P}<0.05$ \\
& & & $\mathrm{~S}$ \\
\hline
\end{tabular}

This table no.5 implies that the HEAL nursing strategy was effective in reducing the pain level among knee osteoarthritis patients.

Table No 6:-Comparison of post-test level of functional ability scores between the experimental and control group.

\begin{tabular}{|l|c|c|c|}
\hline Post test & Mean & SD & Unpaired t test \\
\hline Experimental Group & 41 & 3.40 & -11.3726 \\
Control Group & 57.6 & 0.136 & $\mathrm{P}<0.05$ \\
& & $\mathrm{~S}$ & \\
\hline
\end{tabular}

Table no.6, revealed that the HEAL nursing strategy was effective in improving the functional ability among the knee osteoarthritis patients

\section{Discussion:-}

The main focus of this study was to test the reliability and feasibility of the data collection tools and intervention and its acceptability and effectiveness in reducing the pain and improving the functional ability of adults with knee osteoarthritis. The results indicated that tools used were highly reliable.

The pilot study also showed that the sampling technique, set inclusion and exclusion criteria were appropriate for sample selection. The method of administering the HEAL nursing strategy, the teaching methods selected and the proposed analytical measures were suitable for the study. The comparison between the groups showed that there was a statistical significance. The overall plan was effective, feasible and practicable to be applied in the main study.

\section{Conclusion:-}

The pilot study on the effectiveness of HEAL nursing strategy on pain and functional ability for knee osteoarthritis. The Data collection tools used were reliable, feasible and appropriate to be applied to the samples in the main study and the Heal nursing strategy was effective in reducing the pain and improve the functional ability significantly among the adults with knee osteoarthritis. 


\section{References:-}

1. Haq SA, Darmawan J, Islam MN, Uddin MZ, Das BB, Rahman F, et al. Prevalence of rheumatic diseases and associated outcomes in rural and urban communities in Bangladesh: A COPCORD study. J Rheumatol. 2005 $\mathrm{Feb} ; 32(2): 348-53$.

2. Iqbal MN, Haidri FR, Motiani B, Mannan A. Frequency of factors associated with knee osteoarthritis. JPMAJournal of the Pakistan Medical Association. 2011; 61(8):786-90.

3. Jebakani D, Effect of Therapeutic Exercise on Pain and Psychological well-being in Patients with Knee Osteoarthritis, Indian Journal of Physiotherapy and Occupational Therapy - An InternationalJournal,2015,9(1):147-52

4. Remyamohan,A Comparative Study to Evaluate the Effect of Warm Mustard Oil vs Warm Mustard Oil with Camphor on Relief of Knee Joint Pain among Rural Women in Selected Areas of Puducherry, Indian Journal of Public Health Research \& Development2015,6(4):35-8. 